\section{Estratégias e Políticas de Preço \\ no Mercado de Aviação: caso da \\ Gol Transportes Aéreos ${ }^{1}$}

\section{Wilian Ramalho Feitosa ${ }^{2}$}

RESUMO: A recente entrada da empresa Gol - Linhas Aéreas Inteligentes - no mercado aéreo trouxe de volta a guerra tarifária ao mercado aéreo nacional. Por razão da Gol trabalhar com preços reduzidos, a diminuição de preços foi adotada por todas as grandes empresas, com exceção da Varig, a empresa líder. Os principais produtos das empresas aéreas, as pontes aéreas entre Rio e São Paulo, Rio e Belo Horizonte, São Paulo e Belo Horizonte e São Paulo e Curitiba estão bem mais baratas. Estariam as empresas aéreas preparadas para esse novo contexto de negócios? O fato de viagem aérea ser produto tradicionalmente considerado sofisticado influenciaria na decisão do consumidor? Compara as políticas de marketing das empresas aéreas nacionais e o seu posicionamento de mercado, analisando diferentes políticas de preço e estratégias possíveis e compreendendo a dinâmica do mercado aéreo mundial e suas tendências.

PALA VRAS-CHA VE: mercadoaéreo, companhia aérea, política de preço, Gol (low-cost/low-fair).

ABSTRACT:The recent coming of Gol - Smart Airline Comapnhy - in the Brazilian aircraft market impacted this market, specially the domestic rote. By working with low prices, Gol brought the "fair war". All the bigger comapnies, excepedt Varig, the biggest one, adopted lower prices. The main domestic rotes: São Paulo to Rio de Janeiro, são Paulo to Curitiba and São Paulo to Belo Horizonte, are cheaper than before its coming. But are the companhies prepared for this new congtext? Could the

1. Trabalho de Conclusão de Curso apresentado ao Departamento de Administração, área de Marketing, da Faculdade de Economia, Administrą̧ão e Contabilidade da Universidade de São Paulo

2. Bacharelem Administraçãode Empresas na Faculdade de Economia, Administraçāoe Contabilidade da Universidado

Evillinwally@yahoocombr service by poorer people change its stralegies? The goal of this study is to compare the marketing strategies of the. airline companies, its positioning, by analyzing price policies and othersstrategies, understanding the worldwide airline market chnamic and verifying its trends.

KEYWORDS: air transport market, airline companies price policies, Gol (low-cost/low-fair).

\section{Introduçāo}

O mercado turístico é um dos que mais crescem no mundo. Sua posição de indústria honrada, de baixo investimento inicial, é uma grande possibilidade para o Brasil e para o mundo nos próximos anos.

O mercado aéreo é o grande incentivo do mercado turístico. Através dele, são vencidas rapidamente grandes distâncias. Sua importância para o desenvolvimento econômico é muito grande, assim como a integração de quaisquer países. O mercado aéreo, apesar de sua importância, está passando por um momento precário. Uma série de eventos, nacionais e mundiais, jogou as empresas no limbo financeiro. Grandes dívidas, falências, demissões, prejuízos.

Paralelo a isso, uma parte das empresas nacionais iniciaram um processo intenso de redução das tarifas, com o objetivo de competir mais agressivamente. Dentre estas, encontram-se a Tam e a Gol. Duas cmpresas nacionais, a primeira é a segunda em participação no Brasil para passagens domésticas c a segunda está no estágio inicial, tendo acabado de completar um ano, mas com grandes perspectivas e metas ousadas.

O presente estudo iniciou-se com um estudo exploratório de campo, buscandocompreender a dinâmica deste mercado. Nessa etapa, utilizou-se um questionárjo base para entrevistas com profissionais da área.

Passada essa ctapa, realizou-se um cstudo aprofundado do setor, buscando estatísticas mundiais e nacionais, características das empresas aéreas nacionais, em especial Tame Gol, buscou-se identificar os fatores-chave de sucesso para o negócio companhia aérea, seus desafios e oportunidades. Além disso, buscou-se caracterizar o mercado aéreo como partc do mercado turístico.

A seguir, analisa-se a empresa Gol enquanto empreendimento e parte-se para verificar seus pressupostos.

A base para o empreendimento da empresa Gol Transportes Aéreos está na suposição que existe uma demanda reprimida no mercado aéreo brasileiro, assim como um grande potencial de crescimento. Esta demanda pode estar relacionada ao grupo de consumidores sensíveis a preço.

Por "sensível a preço" entende-se jovens, idosos, passageiros da classe C, consumidores insatisfeitos com a atual política de preços das empresas, entre outros 
O presente estudo, dessa forma, realizou uma "cross-section" entre 16 países, relacionando seu consumo de produtos turísticos, incluso passagens aéreas, e seu produto interno bruto per capita, verificando seu grau de correlação.

O objetivo é verificar se o consumo turístico está relacionado ao nível de renda de cada país, e apontar, com isso, eventuais oportunidades ou ameaças ao mercado aéreo.

Além disso, busca-se julgar a possível eficiência das reduções de preço em face ao posicionamento brasileiro.

\section{Consideraçōes Teóricas}

\section{Políticas de Preços}

Para Bemardi (1996), as práticasou políticas de apreçamento mais comumente observadas são:

a) penetração de mercado;

b) market skimming;

c) recuperação de caixa o mais rápido possível;

d) satisfação e promoção na linha de produtos.

Para que a empresa mantenha seu objetivo de sobrevivência a longo prazo, ela deve empregar adequadamente as políticas de apreçamento, que por sua vez dependem de incorporar claramente as interpretações dos decisores a respeito do mundo que os cerca, ainda que estes não o percebam de forma tão analítica.

A penetração de mercado é aquela política em que a empresa estabelece um preço relativamente baixo, quando comparado com o custo do produto, para estimular a venda de seus produtos, pois seu intuito é o de capturar para si a fatia do mercado almejada.

No market skimming, ou "nateamento", a empresa tira vantagem por determinar um preço do produto elevado, obtendo uma margem de lucro superior, embora seja possível ofertar esse produto a um preço inferior. Em outras palavras, o retorno obtido pela empresa será superior ao encontrado no mercado. Como consequiência imediata, o preço da ação será elevado - já que os investidores têm expectativas de retorno superiores à média do mercado.

A estratégia de apreçamento para a recuperação de caixa o mais rápido possível é utilizada por empresas cuja incerteza sobre o futuro é grande. Empresas incorporamo fator incerteza aos seus preços, principalmentequando defrontam com a demanda fluída e difícil de cativar, características de produtos no estágio introdutório de seu ciclo de vida. Como os consumidores desconhecem ou sabem muito pouco sobre o produto, ou seja, a avaliação do próprio mercado é incerta, a política a ser perseguida é a de minimizar o risco mediante a recuperação do investimento da maneira mais rápida possível. A empresa deve procurar tirar vantagem da novidade existente no produto - fator comportamental existente em camada social elevada, que permite cobrar preços mais elevados.

Preço "satisfatório" é definido como o preço estabelecido com base numa taxa de retorno ou lucro adequada aos "olhos" da firma vendedora. Embora a definição pareça ampla, ela representa o caso específico de mercados monopolistas. Se uma única empresa opera em um mercado, seu objetivo seria o de apreçar o produto para maximizar seu lucro e para não definir um preço que gere um retorno ou lucro satisfatório. A procura do lucro satisfatório é oriunda de uma demanda governamental para evitar uma injustiça social em busca de otimizar as percepções da comunidade.

Na promoção na linha de produtos, a empresa estabelece preços aos produtos que gerarão lucro em toda linha de produtos, em vez de obtê-lo em cada um deles. Esta é uma característica de processos produtivos conhecidos como produtos conjuntos, em que a existência de um deles implica necessariamente a de outro(s).

A idéia da estratégia de preço competitivo é a de desenfatizar a concorrência por via de preço, transferindo o ônus da competição por maiores fatias do mercado aos outros elementos do mix de marketing: produto, distribuição e promoção. Esta estratégia de preço é muito comum em mercados oligopolizados, especialmente do tipo concentrado. A estratégia de preço competitivo consiste em estabelecer o preço do produto da firma em um nível semelhante ao das outras firmas da indústria, que por sua vez já o estabeleceram no nível do preço estipulado pela firma-líder. A razão lógica de tal estratégia baseia-se no receio de uma acirrada competição de preços, que possa levar à ruína todas as firmas. Neste caso, os consumidores são muito sensíveis ao preço.

\section{Estratégias e Posicionamento}

DiMingo apud Toledo e Hemzo (2000) afirmam que o desenvolvimento de

uma estratégia competitiva deve apoiar-se na análise de pontos fortes e fracos do negócio - da empresa e de seus concorrentes - e no estabelecimento de uma oferta diferenciada.

Em Kotler(1998), posicionamento é o ato de desenvolver a oferta e a imagem da empresa, de maneira que ocupem uma posição competitiva distinta e significativa nas mentes dos consumidores-alvos.

DiMingo apud Toledo e Hemzo (2000) afirmam que

o verdadeiro posicionamento é o processo de distinguir uma empresa ou um produto de seus competidores com base em dimensōes reais - produtos ou valores significativos para seus consumidores - para a empresa ou produto preferido do mercado. 


\section{Custo versus Diferenciaçāo}

Em Besanko et al. (2000), apesar de não existir uma regra definitiva, o mercado do produto e as posições das empresas na indústria tornam uma estratégia mais adequada que a outra.

Construir a vantagem competitiva com base em custosé melhor nas seguintes situações:

a) economias de escala e de aprendizagem são significantes, mas nenhuma firma as explora;

b) os produtos são commodities;

c) os consumidores são bastantes sensíveis a preço;

d) o produto é u m bem de procura e não um bem de experiência. Um bem de procura é um produto que se pode avaliar os atributos de qualidade antes da compra.

Construir a vantagem competitiva com base em benefício é melhor nas seguintes situações:

a) os consumidores pagariam mais por atributos que aumentam o benefício

b) economias de escuala e aprendizagem são significantes eempresas já as exploram; c) o produto é um bem de experiência e não um bem de procura.

\section{Ofensivas versus Defensivas}

Em Hooley e Saunders (1996), muitos setores industriais possuem uma empresa que é reconhecida como líder de mercado. Essa empresa tem a maior participação no mercado relevante do produto. Geralmente, lidera as outras empresas em termos de mudanças de preços, lançamentos de novos produtos, cobertura de distribuição e intensidade promocional. A líder pode ou não ser admirada ou respeitada, mas as demais empresas reconhecem sua dominância. Ela é ponto de orientação das empresas concorrentes que a desafiam, imitam ou evitam.

A menos que uma empresa dominante desfrute um monopólio legalmente reconhecido, sua vida não é nada fácil. Deve manter vigilância constante porque outras empresas podem desafiar suas forças ou tirar vantagens de suas fraquezas. A líder de mercado pode facilmente falhar e cair para o segundo ou terceiro lugar. A líder pode gastar de modo conservador, precavendo-se de tempos difíceis, enquanto uma desafiante gasta deliberadamente. A líder pode menosprezar a concorrência e ser passada para trás. A empresa dominante pode parecer antiquada em relação às rivais mais novas e agressivas. Os custos da empresa dominante podem ser excessivamente elevados, prejudicando o seu lucro. As empresas que ocupam a segunda terceira ou classificações mais baixas em um setor industrial são, frequientemente, chamadas de desafiantes de mercado. Há muitos casos de desafiantes de mercado que ganharam terreno da líder de mercado ou chegaram a supera-la.

Dolan apud Hooley e Saunders (1996) constatou que a rivalidade competitiva e a redução de preços são mais intensas em setores industriais com custos fixos, custos de estoque elevados e demanda primária estagnada, como aço, automóveis, papel e produtos químicos.

\section{Ocupante de Nicho}

Para Kotler (1998), uma alternativa para tornar-se seguidora em um grande mercado é ser líder em pequeno mercado ou nicho. Normalmente, as empresas menores direcionam-se a pequenos mercados, de pouco ou nenhum interesse das grandes empresas.

Os nichos costumam ser muito rentáveis. A principal razão é que a empresa ocupante de nicho termina conhecendo o grupo-alvo de consumidores tão bem que atende as suas necessidades melhor do que outras empresas que, casualmente, vendem a esse nicho. Como resultado, a ocupante de nicho pode cobrar uma margem substancial sobre os custos em função do valor agregado oferecido. Ela obtém margem alta, enquanto a empresa que vende em massa consegue volume alto.

As ocupantes têm três tarefas: criar, expandir e proteger nichos. A empresa ocupante de nicho tem um grande risco porque ela pode desaparecer ou ser atacada. Ela fica presa a recursos especializados que podem não ter usos altemativos de alto valor.

\section{Empresas seguidoras de Mercado}

Segundo Kotler (1998), muitas empresas seguidoras preferem acompanhar a desafiar a líder de mercado. O esforço para atrair consumidores da líder nunca é desconsiderado por esta. Se a ação da desafiante for baixar preços, melhorar serviços ou acrescentar características no produto, a líder pode, rapidamente, fazer o mesmo para dispensar o ataque. Provavelmente, a líder tem mais poder de resistência em todo o campo de batalha. Uma luta árdua pode deixar ambas as empresas em pior situação, significando que as empresas seguidoras devem pensar cuidadosamente, antes de atacar. A menos que a empresa possa lançar um ataque substancial do produto ou revolução na distribuição, ela prefere, freqüentemente, acompanhar em vez de atacar a líder. 


\section{Análise do Mercado}

O mercado aéreo mundial tem sua demanda influenciada por diversos fatores. Segundo Garófuro (1982), esses fatores podem ser divididos em fatores econômicos e qualitativos. Nos fatores económicos podemos citar: renda, tarifa, duração da viagem, frequiência do scrviço, população e distância. Já nos fatores qualitativos podemos citar: conforto, condições climáticas, prestígio/status, acesso aos aeroportos, propaganda/publicidade, qualidade do serviçoe variáveis geopolíticas.

Com relação a custos, as empresas brasileiras comportam-se conforme : distribuição da Figura 1. As mudanças econômicas c principalmente a variação cambial afetam sobremaneira o mercado de transporte aéreo no País, uma vez que as peças e acessórios, bem como aeronaves são comprados ou alugados com valor em dólar.

A demanda por viagens aéreas pode ser dividida $\mathrm{cm}$ dois grupos principais: passageiros que viajam a turismo c a negócios. No Brasil, o turismo de negócios é o de maior monta $(71 \%)$, explicando o grande fluxo entre as principais capitais, conforme demostrado na Figura 2.

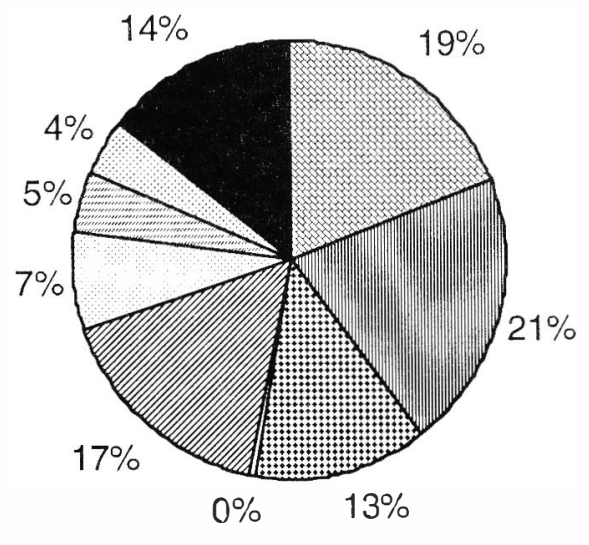

由:⿴囗十) Combustivel
$\square$ Amortizações
$\square$ Tarifas Aeronáuticas
Depreciação, seguro e
aluguel
OOrganização Terrestre
Outros

FIGURA 1 - COMPOSIÇÃO DOS CUSTOS DAS EMPRESAS AÉREAS (1999)

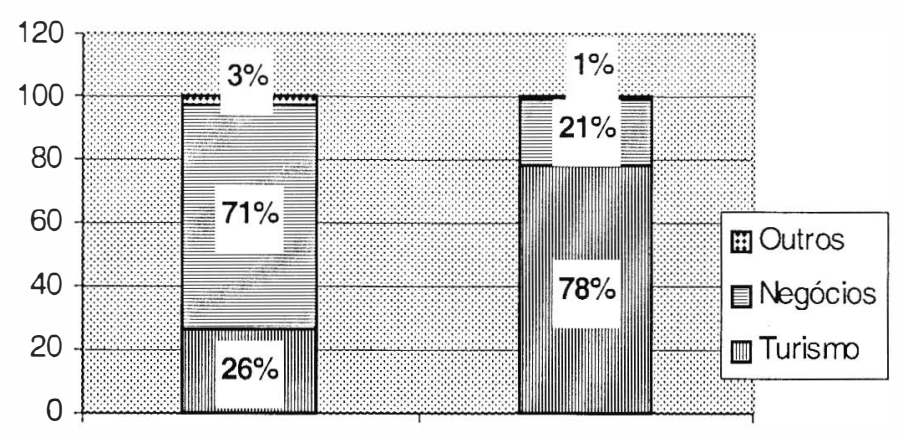

Fonte: SNEA / Gazeta Mercantil - BNDES

\section{FIGURA 2 - PERFIL DA DEMANDA (1999)}

A lucratividade do mercado aéreo brasilciro para as empresas nacionais não têm sido nada boa. Não só a situação cconômica como os custos elevados têm colocado as empresas do setor no vermelho. Estão incluídas na Tabela 1 e na Figura 3 a Tam meridional, Vasp, Varig e Transbrasil.

Em 1998, houve uma disputa tarifária para os mercados domésticos e intentacional, graças inclusive ao alargamento da banda tarifária concedida pelo Departamento de Aviação Civil (Dac) e a necessidade de otimizar o índice de ocupação das naves, considerando o baixo índice de aprovcitamento médio até aquele momento. Porém, mesmo com um aumento de $23 \%$ na demanda em termos globais e sem o aumento de frota, o aumento foi de apcnas 6,7\% em relação ao exercício de 1997, não sendosuficiente para compensar o aumento de gastos com as promoções, fazendo as empresas apresentar a queda de $87 \%$ em seus resultados.

Com a mudança da política cambial c a consequiente desvalorização de nossa moeda em 1999, a atividade de transporte aéreo foi profundamentc afetada, tanto pela elevação dos custos, noqual o componente câmbioé de grande rcpresentividade, quanto pela retração das receitas, tendo em vista a diminuição constatada na demanda, especialmente no mercado internacional.

No mercado doméstico, a retração na demanda foi de $6 \%$ em relação a 1998 e com isso, o índice de aproveitamento caiu para $54 \%$. No mercado internacional, a demanda caiu $18 \%$, fazendo o índice atingir $61 \%$ de 1999. Em 2000 a situação evoluiu um pouco, mas algumas empresas permaneceram mergulhadas em dívidas.

Já no mercado internacional tem sidodiferente. Houve a fase de reestruturação decustos e de perfil. Esse movimento ocorreu ao longo de toda a década de 90. Após um período de crise, no começo dos anos 90 , o mercado reduziu os custos e o valor de cada transação, assim como sua lucratividade, elevando o número de transações. Como isso, voltou a ter lucros. O tráfico internacional aumentou sensivclmente ao longo da década de 1990, quase duplicando, cnquanto a reccita média caiu e a receita bruta está ao nível da inflação. 
TABELA 1 - TARIFA PARA O MERCADO DOMÉSTICO INTERNACIONAL

\begin{tabular}{|c|c|c|c|c|c|c|c|c|c|c|c|c|}
\hline & \multicolumn{3}{|c|}{ Tráfego doméstico } & & \multicolumn{4}{|c|}{ Tráfego internacional } & \multicolumn{4}{|c|}{ Total } \\
\hline & & 1998 & 1999 & $\begin{array}{l}2000 \\
\text { (até } \\
\text { set.) }\end{array}$ & 1997 & 1998 & 1999 & $\begin{array}{l}2000 \\
\text { (até } \\
\text { set.) }\end{array}$ & 1997 & 1998 & 1999 & $\begin{array}{l}2000 \\
\text { (até } \\
\text { set.) }\end{array}$ \\
\hline $\begin{array}{l}\text { Receita de Vôo } \\
\text { (R\$ milhöes) }\end{array}$ & 2739 & 3920 & 3306 & 3007 & 2980 & 3043 & 3529 & 2772 & 5738 & 5965 & 7035 & 5779 \\
\hline $\begin{array}{l}\text { Resultado de Vôo } \\
\text { (R\$ milhöes) }\end{array}$ & 347 & 119 & -72 & 113 & -79 & -83 & -196 & -81 & 265 & 35 & -203 & 19 \\
\hline $\begin{array}{l}\text { Assento km. Oferecido } \\
\text { (milhōes) }\end{array}$ & 22895 & 27966 & 28953 & 22179 & 42240 & 42550 & 36621 & 25196 & 65135 & 70516 & 65574 & 47375 \\
\hline $\begin{array}{l}\text { Pax. km. Transportado } \\
\text { (milhöes) }\end{array}$ & 13432 & 16588 & 15569 & 13047 & 27897 & 27489 & 22464 & 18066 & 41328 & 44077 & 38033 & 33107 \\
\hline Aproveitamento (\%) & 58.7 & 59.3 & 53.8 & 58.8 & 66 & 64.6 & 61.3 & 71.7 & 63.5 & 62.5 & 58 & 65.7 \\
\hline Custo Ass. km (R\$) & 0.1054 & 0.1002 & 0.1214 & 0.1305 & 0.0724 & 0.0735 & 0.1017 & 0.1132 & 0.084 & 0.0841 & 0.1104 & 0.1213 \\
\hline Vield pax. km (R\$) & 0.2054 & 0.1761 & 0.2252 & 0.2306 & 0.1068 & 0.1108 & 0.1571 & 0.1514 & 0.1389 & 0.1353 & 0.185 & 0.1858 \\
\hline Break-Even (\%) & 51.3 & 56.9 & 53.9 & 56.6 & 67.8 & 66.4 & 64.7 & 73.9 & 60.5 & 62.1 & 59.7 & 65.3 \\
\hline Ton. km. Utiliz. (milhōes) & 1291139 & 1537081 & 1570933 & nd & 3806099 & 3708553 & 3086126 & nd & 5097239 & 5245633 & 4657057 & nd \\
\hline
\end{tabular}
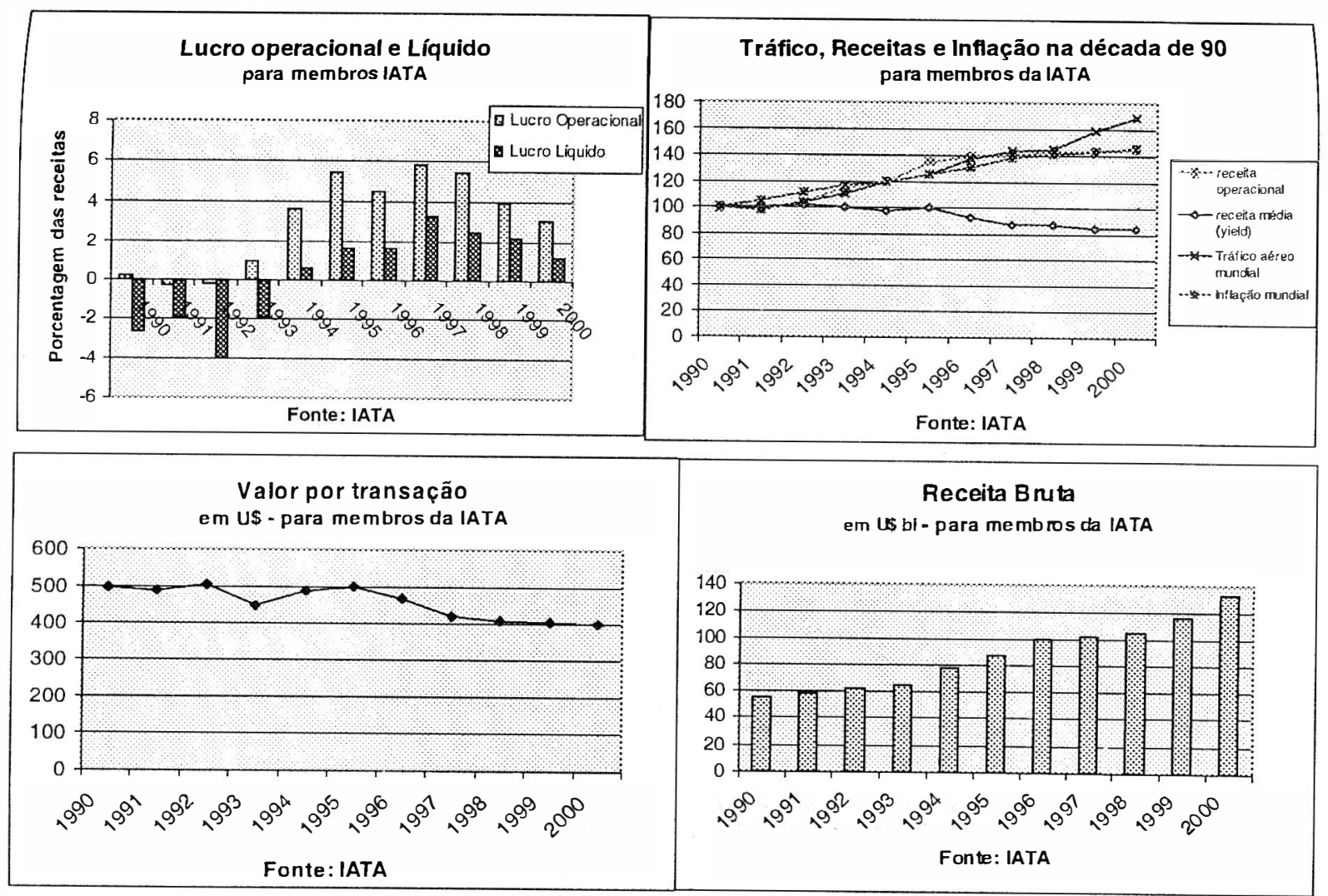
Espera-se para a próxima década um grande crescimento neste mercado, especialmente em países em desenvolvimento, como os da América Latina, a Rússia e a China.

\section{TAM e GOL}

\section{Caracteristicas e Estatisticas}

A Tam Transportes Aéreos S/A acredita que é preciso perseguir duas estratégias básicas:

a) diferenciação dos serviços oferecidos;

b) eficiência operacional.

A diferenciação que a Tam tem procurado obter em relação aos seus concorrentes diretos tem um foco: exemplo, conquistar o segmento de mercado mais rentável - viagens de negócios.

Para tal, a Tam tem procurado fazer com que seus clientes percebam o diferencial qualitativo de seus serviços. Dentre as principais estratégias praticadas para enfrentar a concorrência, destacam-se vôos para aeroportos centrais e vôos diretos nos horários de maior demanda. Em termos de serviços, a Tam tem proporcionado lanches e bebidasem suas salas de embarque, além de música ao vivo, em Congonhas. Oferece ainda, serviços gratuitos de estacionamento, em Congonhas, e transporte em ônibus próprio entre os aeroportos de Cumbica e Congonhas. Mas a grande arma da Tam é oferecer o programa de fidelização de clientes. Além disso, usa do patrocínio aos esportes e uma assessoria de comunicação eficiente.

Já a Gol Transportes Aéreos surgiu com a proposta de ser uma empresa low-costllow-fair, ou seja, uma empresa de baixos custos e, por isso, pode praticar baixos preços sem sacrificar as margens de lucro. Para tal, reduziu seus custos através dos seguintes passos: alto uso de tecnologia, frota padronizada e nova, vôos noturnos, rotas alternativas, utilização de "hubs", baixo tempo de solo, alta produtividade, serviço de bordo simples e grande produtividade.

Seu público está dividido conforme abaixo:

- $64 \%$ tem nível de graduação ou mais;

- $47 \%$ fazem viagens a negócios;

- $98 \%$ querem voar novamente pela Gol;

- $18 \%$ voaram pela primeira vez;

- 59\% micro e pequenos empresários e profissionais liberais. (Fonte: Mattar e Associados - primeiro semestre de 2001)
- Perfil dos usuários:

- consultores;

- pequenos empresários;

- profissionais liberais;

- jovens e aposentados.

- Tipo de pagamento:

- $90 \%$ no cartão (à vista ou não);

- 5\% cheques (Banco Panamericano);

- $5 \%$ balcão dos aeroportos.

TABELA 2 - DADOS COMPARATIVOS DA TAM VERSUS GOL

\begin{tabular}{l|l|l}
\hline \multicolumn{1}{c|}{ Característica } & \multicolumn{1}{|c|}{ TAM } & \multicolumn{1}{|c}{ GOL } \\
\hline Aviōes & $\begin{array}{l}70(40 \text { meridional e } 30 \\
\text { regiona') } \\
1.000 .000\end{array}$ & 10 \\
Passageiros/mês & $\begin{array}{l}\text { Serviço diferenciado / } \\
\text { status } \\
\text { Marketing esportivo / } \\
\text { propaganda e publicidade } \\
\text { Foco }\end{array}$ & $\begin{array}{l}\text { Outdoors(ônibus), } \\
\text { publicidade e propaganda } \\
8,5 \%\end{array}$ \\
Comınicação & $\begin{array}{l}\text { Simples, custo } \\
\text { Pecnologia / conforto }\end{array}$ & Inteligente \\
\hline Imagem &
\end{tabular}

\section{Preços}

A Gol afirma ter preços mais baratos, mas nem sempre isso condiz com a realidade. No dia 30 de novembro de 2001 , foi feita uma pesquisa, utilizando a Internet e o atendimento telefônico de quatro empresas, como pode ser visto na tabela 3.

Em alguns horários e para alguns destinos, a tarifa da Tam ou da Vasp são menores que a da Gol. O fato é que a Tam e a Vasp aderiram a guerra de preços, ao contrário da Varig, que manteve seus preços e, contrariando o que se esperava, não perdeu participação no mercado. Ao menos por ora, a Varig não pretende reduzir preços. 
TABELA 3 - PREÇOS DE SÃO PAULO PARA AS DEMAIS LOCALIDADES $(30 / 11 / 01)$

\begin{tabular}{|c|c|c|c|c|c|}
\hline \multirow[t]{2}{*}{ 10.a } & $\mathrm{gOO}$ & \multicolumn{2}{|c|}{ TAls: } & \multirow{2}{*}{$\begin{array}{c}v A s p \\
\text { Reduzida } \\
(R \$)\end{array}$} & \multirow{2}{*}{$\frac{V^{4} q^{\prime}}{(R \$)}$} \\
\hline & Mike $(\mathrm{R} \$)$ & $\begin{array}{c}\text { Congonhas } \\
(R \$)\end{array}$ & $\begin{array}{c}\text { Cumbica } \\
(R \$)\end{array}$ & & \\
\hline Porto Alegre & 183,00 & 334,00 & 198,00 & 234,00 & 711,35 \\
\hline Florianópolis & 154,00 & 248,00 & 151,00 & 189,00 & 493,40 \\
\hline $\begin{array}{l}\text { Rio de } \\
\text { Janeiro }\end{array}$ & 96,00 & $128,00(105,00)$ & $210,00(106,00)$ & 138,00 & 416,50 \\
\hline Curitiba & 82,00 & $222,20(105,00)$ & $119,25(111,00)$ & 137,00 & 209,40 \\
\hline Recife & 447,00 & 658,00 & 580,00 & 405,00 & 2108,40 \\
\hline Salvador & 301,00 & 473,00 & 296,25 & 400,00 & 1664,00 \\
\hline Brasilia & 146,00 & 179,00 & 324,00 & 235,00 & 888,00 \\
\hline Belém & 286,00 & 544,20 & 630,00 & 526,00 & 1429,35 \\
\hline $\begin{array}{l}\text { Campo } \\
\text { Grande }\end{array}$ & 159,00 & 345,20 & 153,25 & 145,00 & 684,00 \\
\hline Cuiabá & 189,00 & 226,00 & 183,25 & 175,00 & 992,40 \\
\hline $\begin{array}{l}\text { Belo } \\
\text { Horizonte }\end{array}$ & 136,00 & 182,00 & - & 177,00 & 203,70 \\
\hline
\end{tabular}

1. Gol não pratica tarifas uniformes; as tarifas variam conforme o vôo. Os valores correspondem a tarifa Mike, uma das diferentes modalidades de preço.

. (1) eçó menor.

3. Os valores referentes à Variy são de ida e volta, pois este é o seu formato de vendas.
Como a estrutura interna da Gol é diferente, as outras empresas têm as seguintes opções com relação aos preços:

- reduzir permanentemente: repensar a frota, desburocratizar, reduzir sistemas de controle de vendas, demitir efetivo, reposicionar a marca;

- reduzir temporariamente: ineficiente, pois a Gol não pretende aumentar os seus.

\section{Apresentação e Análise dos Dados}

Inicialmente foi considerado para os estudos um grupo de 13 países, como pode ser visto na Figura 4. São países escolhidos pela sua representatividade em relação ao mundo no que se refere à (ao):

- distribuição geográfica;

- potencial de atração turística;

- tamanho do país;

- nível de renda.

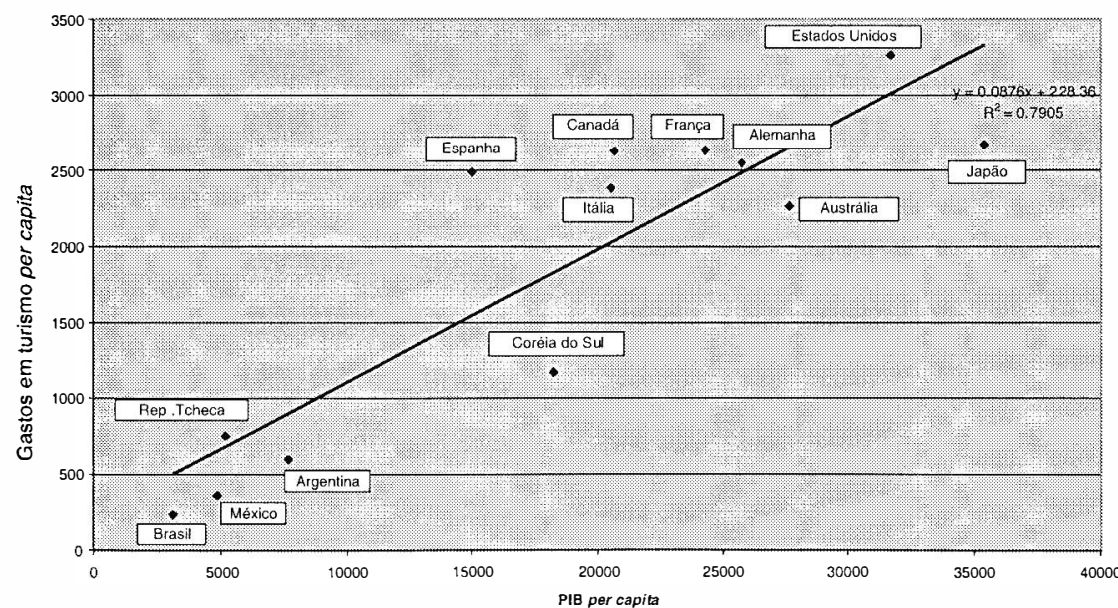

\section{FIGURA 4 - MIX DE PAÍSES DESENVOL VIDOS E EM DESENVOL VIMENTO}

Foram escolhidos, dessa forma, países desenvolvidos ou em desenvolvimento, de pouco ou grande extensão, similares ou diferentes ao Brasil, em que todos os dados desse estudo foram obtidos junto ao WTTC (World Travel and Tourism Council), FMI (Fundo Monetário Internacional), Macrométrica, Fipe e Encarta. Os resultados obtidos revelaram um $\mathrm{R} 2$ igual a 0,7905 , revelando uma correlação acima do nível crítico de 0,7 , ou seja, as variáveis PIB per capita e gastos com turismo são altamente correlacionadas.

Outro resultado observávelé que alguns países se localizaram abaixo da linha de tendência, o que pode indicar uma oportunidade de investimento em turismo. 
Acerca do posicionamento em relação à linha de tendência, foi observado a seguinte distribuição:

- países com grande PIB per capita, mas com gasto em turismo abaixo da linha de tendência: Japão, Austrália e Coréia do Sul. Podem ser chamados de países aversos ao turismo, pois sua população consome menos do que, em tese, poderia;

- países com grande PIB per capita e localizados acima da linha de tendência: França, Canadá, Espanha e Itália. Podem ser chamados de países com maior propensão ao turismo, pois têm gastos mais elevados;

- países com pequeno PIB per capita e localizados abaixo da linha de tendência: Brasil, México e Argentina. Podem ser chamados de consumidores potenciais ou não consumidores involuntários;

- países com pequeno PIB per capita e localizados acima da linha de tendência: República Tcheca.

Foi observado que os países com elevado desenvolvimento econômico, em especial os da Europa e América no Norte, tiveram desempenho acima da linha de tendência, enquanto países em desenvolvimento estiveram abaixo, exceto a República Tcheca. É possível que, dado suas características difenciadas, esses países não se constituem exemplos de desempenho aplicáveis ao Brasil.

Dessa forma, repetiu-se o exercício, dessa vez com 7 países com características econômicas mais próximas ao Brasil, com exceção da República Tcheca, por se considerar que, pelo fato de estar em uma região rica em opções turísticas, sua população tende a ter gastos mais elevados. (Figura 5).

Desta vez o índice $\mathrm{R}^{2}$ foi extremamente elevado, 0,99, muito próximo de 1 , o que revela que a correlação entre PIB per capita e gastos em turismoé mais elevada nesta seleção de países.

Verificou-se que o único país acima da linha de tendência é a Argentina. Os demais se encontram abaixo ou próximos da linha.

\section{Conclusão}

O estudo realizado demonstrou que pode ser arriscado prever uma evolução significativa no nível de gastos em turismo, pois o Brasil encontra-se em um patamar dentro da linha de tendência mundial para países semelhantes a ele economicamente. Entretanto, o estudo não considerou a tendência mundial, apontada no item "Considerações Teóricas"'. Pode-se observarque as maiores companhias aéreas mundiais reduziram ao longo da década de 90 o valor por transação, ao mesmo tempo em que aumentaram sua lucratividade operacional.

Essa tendência ainda não se concretizou em países em desenvolvimento. É exatamente essa a opção da Gol transportes aéreos no Brasil. Pode ser a solução a médio prazo para o mercado aéreo brasileiro, envolto em crises de custos.

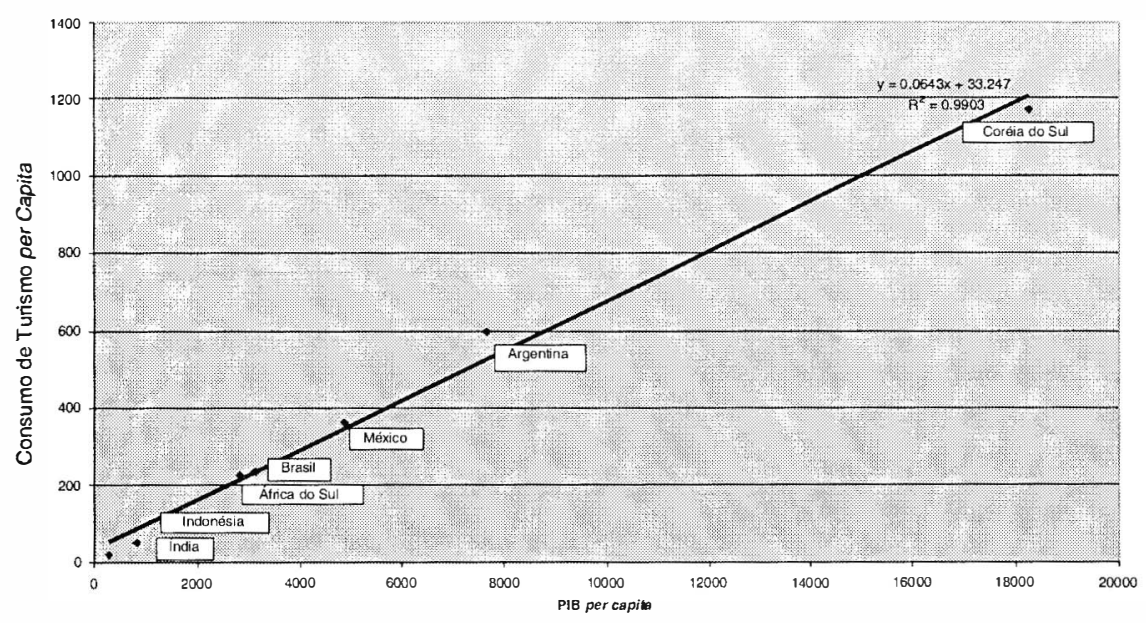

\section{FIGURA 5 - SOMENTE PAISES EM DESENVOLVIMENTO}

O estudo representa um quadro atual, e não uma tendência temporal. Mas seu resultado não pode ser desprezado. Os desafios que o Brasil enfrenta, os demais países em desenvolvimento também enfrentam. O estudo tem como limitação não considerar as diferenças culturais entre os países envolvidos na pesquisa.É possível que existam países com maior propensão ao turismo dada a sua cultura, que dão maior valor ao conhecimento de outras regiões ou países, enquanto haja outras culturas que valorizam a família, a permanecer na mesma cidade, na mesma região. Outra limitação está no PIB per capita. Esta medida pode mascarar os resultados, uma vez que o câmbio, especialmente em países em desenvolvimento, é muito volátil, gerando distorções nos preços relativos entre países. O resultado poderia ser melhorado se fosse utilizado o conceito de paridade do poder de compra, no qual o PIB per capita é calculado baseado no poder de compra efetivo da moeda em relação a uma cesta de produtos. Um exemplo da diferença dessa medida no estudo é o caso brasileiro. Pelo método utilizado, seu PIB per capita é US\$3100, enquanto o PIB per capita PPP, em 2000, foi US\$7200.

A iniciativa da Gol atrai um público que ainda não tinha voado. Apesar de sua comunicação estar mais voltada ao pequeno empresário e ao profissional liberal, este público foi atraído pela sua proposta. O fato de ter custos reduzidos pode levá-la ao sucesso, qual suas congêneres nos EUA. Apesar dessas características, a Boing crê em uma década de alto crescimento no mercado aéreo dos países em desenvolvimento, tais como os países da América Latina, Ásia e a China.

Entretanto, cabe a Gol considerar se as características do mercado brasileiro estão mais próximas dos países em desenvolvimento ou dos países desenvolvidos, e como lidar com as dificuldades de rendado público brasileiro. Podemos considerar, 
portanto, que seu modelo tem maior possibilidade de crescimento do que o da TAM, que esta voltada para os serviços diferenciados.

\section{A Questão da Abertura dos Céus}

Há a possibilidade de, nos próximos anos, o Brasil abrir seu espaço aéreo para a entrada de empresas de outros países. É a chamada “política de céus abertos”. Essa possibilidade deve deixar as empresas aéreas atentas. Seus custos devem ser reestruturados e suas dívidas equacionadas para poder enfrentar a concorrência internacional, muito mais poderosa do que a brasileira.

Para que haja essa reestruturação, é necessário se verificar o porquê de determinados gastos serem tão elevados, como o valor de seguro, o qual é quase o dobro do valor americano, e o Brasil tem o mesmo padrão de segurança e até é certificado. Mas talvez o principal fato seja o aproveitamento dos assentos no Brasil, que é inferior ao padrão internacional. Aqui, o aproveitamento médio é muito próximo ao break-even, o que impacta a lucratividade das empresas e, conseqüentemente, seu poder de concorrer com empresas estrangeiras, maiores e mais lucrativas.

\section{A Questão da Guerra de Preços}

Conforme pode ser observado no item "Análise de Mercado", as empresas Vaspe TAM reduziram seus preços para patamares próximos ao da Gol. A Varig não aderiu a redução de preços. Essa redução, entretanto, trouxe para a Gol, no primeiro semestre de 2001 , somente $18 \%$ de passageiros que voavam pela primeira vez. Supondo que essa relação seja semelhante nas outras companhias aéreas, facilmente chegamos a conclusão que os demais $82 \%$ são passageiros que poderiam, em tese, arcar com os custos de uma passagem mais cara, e que já estavam adaptados aos preços anteriores. Há, portanto, uma perda de receita.

Essa concorrência predatória já ocorreu anteriormente, em 1998. Naquela ocasião, uma redução sistemática nos preços das tarifas levou a Transbrasil a se endividar. Isso, entre outros motivos, tais como a desvalorização cambial, levou-a a concordata em 2001.

A diferença, em relação à outrora, é que a Gol é uma empresa mais eficiente e de menores custos. Mas boa parte dos custos são semelhantes às todas as empresas e inalteráveis. Somando-se as contas - câmbio, combustível e tarifas aeronáuticas temos $40 \%$ dos custos de uma companhia.

\section{Referências}

BERNARDI, Luiz Antonio. 1996. Política e formaçāo de preços. Atlas. BESANKO,D:;

COBRA, M. 2000. Marketing de Turismo. Cobra.

GARÓFARO, G. L. 1982. O mercado brasileiro de transporte aéreo regional. Tese (Doutorado), Instituto de Psicologia, Universidade de São Paulo.

HOOLEY, G. J.; SAUNDERS, J. 1996. Posicionamento competitivo. Makron books.

INSTITUTO BRASILEIRO DE TURISMO. EMBRATUR. s.d. Estudos do turismo brasileiro. Brasília. Embratur.

KOTLER, P. 1998. Administraçāo de marketing: análise, planejamento, implementaçāo e controle. Atlas.

AGE, B.; MILONE, P. 2001. Economia do turismo. Atlas.

2000. Turismo: teoria e prática. Atlas.

LINNEMAN, R.; STANTON JR., J. 1995. Marketing de nichos. Makron Books.

MATTAR, F. N.;

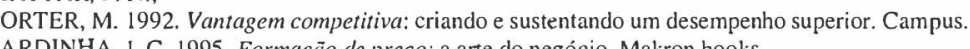

Formação de prȩ̣o: a arte do negócio. Makron books.

OLEDO, G. L.

\section{Recebido em 24/1/2002}

